\title{
Ocular toxicity of desferrioxamine - an example of copper promoted auto-oxidative damage?
}

\author{
H PALL,' D R BLAKE, ' P WINYARD, ${ }^{1}$ J LUNEC, ${ }^{1}$ A WILLIAMS, ${ }^{1}$ \\ P A GOOD, ${ }^{2}$, E E KRITZINGER, ${ }^{2}$ A CORNISH, ${ }^{3}$ AND R C HIDER ${ }^{3}$
}

From the 'Departments of Neurology and Rheumatology, the Medical School, University of Birmingham, Birmingham B15 2TJ; ${ }^{2}$ Birmingham and Midland Eye Hospital, Church Street, Birmingham B3 2NS; and the ${ }^{3}$ Department of Chemistry, University of Essex, Colchester CO4 3SQ

SUMmaRY Three patients with rheumatoid disease were given the 'iron chelating' drug desferrioxamine (DFX), which also has an appreciable affinity for copper. The drug was injected cautiously, in lower doses than in patients with thalassaemia, and intramuscularly to evaluate its anti-inflammatory effects. Two of the three patients developed ocular abnormalities. One patient, who also received methyldopa, developed severe but reversible visual failure associated with an abnormal electro-oculogram (EOG); another showed reversible depression of the EOG. Analysis of the cerebrospinal fluid (CSF) of this patient showed an increase in phenanthroline detectable (non-caeruloplasmin-bound) copper. Analysis of the CSF of the third patient, who did not develop any clinical or electrophysiological ocular abnormalities, was normal. Haematological assessments indicated that all three patients probably had reduced iron stores. With in-vitro systems DFX was shown to mobilise copper from albumin and to facilitate copper movement across a cell membrane model, a property that was enhanced by methyldopa. Our observations are consistent with the concept that in rheumatoid patients low iron stores may result in binding of copper by DFX and that this may be of central importance in causing the ocular toxicity of DFX.

We have described previously details of three patients with rheumatoid arthritis who developed ocular problems after the subcutaneous infusion of desferrioxamine (DFX). ${ }^{1}$ In one case DFX was given in conjunction with the phenothiazine, prochlorperazine. This patient lost consciousness, and analysis of his cerebrospinal fluid (CSF) showed a decrease in loosely bound (catalytic) iron. He subsequently developed an optic neuropathy and pigmentary retinopathy. This was associated with abnormalities of the electro-oculogram (EOG) and electroretinogram (ERG), the former recovering within 18 months, the latter failing to recover. These disturbances were associated with a rise in CSF noncaeruloplasmin bound ('catalytic') copper, with values becoming normal after seven months. DFX was subsequently shown to act synergistically with prochlorperazine by in-vivo and in-vitro studies. Our results tentatively suggested that DFX alone or DFX in combination with prochlorperazine may have Correspondence to H Pall, Neurology Department, Addenbrooke's Hospital, Cambridge CB2 2QQ. liberated copper, inducing oxidative damage within the neural tissue including retina. ${ }^{1}$ We have presented some evidence recently that this may be the case for phenothiazine drugs. ${ }^{2}$

Our clinical studies, which were designed to assess the efficacy of DFX as an anti-inflammatory compound in rheumatoid disease by inhibiting ironpromoted oxidative damage were then stopped. However, following reports by Giordano et al. ${ }^{34}$ that lower doses of intramuscular DFX (1 g every 14 days) increased the haemoglobin concentration in rheumatoid patients, and apparently suppressed inflammation without 'reported' side effects, ethical committee approval was obtained for continued studies at the lower dosage regimen. We extend the clinical and biochemical studies and describe in-vitro studies that support the case for copper mediated mechanisms of damage in DFX toxicity.

Three cases are presented. Of these one patient who received only $5 \mathrm{~g}$ of DFX in conjunction with methyldopa developed marked bilateral retinal oedema, a pigmentary epitheliopathy, and grossly 
abnormal responses to ocular electrodiagnostic tests. Another, receiving a total of $14 \mathrm{~g}$ of DFX, showed an asymptomatic ocular disturbance detected by electrophysiological testing. Our subsequent in-vitro studies provide further insight into the mechanism of these effects and support the view that the ocular changes can, in principle, result from copper promoted oxidative damage within the interphotoreceptor matrix and retinal pigment epithelium (RPE), with particular damage occurring to the photoreceptor outer segments.

\section{Material and methods}

EOG and ERG studies were performed in accordance with the following protocols. The EOGs were recorded by the technique outlined by Arden et al. ${ }^{5}$ ERGs were recorded in scotopic and photopic conditions with Burian-Allen contact lens recording electrodes. All ERGs were obtained by a Ganzfeld stimulus and were averaged with a Nicolet $\mathrm{C} 4$ analyser. In order to obtain a rod dominated response the patients' eyes, once dilated, were dark adapted for 15 minutes, and a low-intensity white light was used. A cone dominated response was obtained by light adapting the eyes and then using a $30 \mathrm{~Hz}$ red stimulus.

The visual evoked responses (VER) (recorded only in patient 3 ) were obtained by means of flash and pattern stimulation, with two-channel bipolar recordings, 10/20 system electrode placement. The responses were recorded on a Nicolet $\mathrm{C} 4$ analyser. Pattern check sizes were $1^{\circ} 50^{\prime}, 50^{\prime}$ and $25^{\prime}$.

Phenanthroline copper was measured as described by Pall et al., ${ }^{6}$ a modification of the method of Gutteridge. ' We have established a 'normal range' of $1.5(0.5) \mu \mathrm{M}$ (mean, SD) derived from $28 \mathrm{CSF}$ samples from patients with a variety of disparate neurological and orthopaedic conditions. ${ }^{6}$ All CSF was collected from the supine patient in the morning with G22 stainless steel disposable needles which we have shown to be free of contamination with copper.

\section{Case reports}

PATIENT 1

A 60-year-old $(53 \mathrm{~kg})$ man with seropositive erosive, destructive rheumatoid disease, with disseminated and cropping rheumatoid nodules, was admitted to the trial, having been unresponsive to 'second line drugs' and poorly controlled on prednisolone EC 10 $\mathrm{mg}$, and naproxen $500 \mathrm{mg}$ twice daily. His ESR was $30 \mathrm{~mm} / \mathrm{h}$ C-reactive protein (CRP) $21 \mathrm{mg} / \mathrm{l}, \mathrm{Hb} 15.7$ $\mathrm{g} / \mathrm{dl}$, ferritin $51 \mu \mathrm{g} / \mathrm{l}$ (normal, $>15 \mu \mathrm{g} / \mathrm{l})$, serum Fe $12 \cdot 2 \mu \mathrm{mol} / \mathrm{l}$ (normal 11-30), total Fe binding capacity $59.6 \mu \mathrm{mol} / 1$ (normal $45-70$ ) [\% saturation
$20 \cdot 5$ (normal $>15)]$. These indices suggested normal iron stores.

In this patient EOGs and ERGs were normal; the EOG being recorded as $170 \%$ in both eyes before treatment and $172 \%$ in the $R$ eye and $167 \%$ in the $L$ eye after treatment. Our normal values for EOG in a rheumatoid population of $>50$ years are $>155 \%$, this value having been obtained from a sample of 65 patients. He received 14 daily intramuscular injections of $1 \mathrm{~g}$ of DFX. At the end of the treatment period his ESR was $20 \mathrm{~mm} / \mathrm{h}, \mathrm{CRP} 25 \mathrm{mg} / \mathrm{l}$, ferritin 22 $\mu \mathrm{g} / \mathrm{l}, \mathrm{Hb} 13.5 \mathrm{~g} / \mathrm{dl}$, serum $\mathrm{Fe} 6.6 \mu \mathrm{mol} / \mathrm{l}$, total $\mathrm{Fe}$ binding capacity $69.4 \mu \mathrm{mol} / /$ [\% saturation $9 \cdot 5$ ]. Clinical assessments of disease activity at the end of the trial period and for the subsequent three months showed no significant change from pretreatment values. A bone marrow estimation performed one month after DFX was discontinued showed a complete absence of iron stores: his iron indices were similar to those at the end of the trial period.

PATIENT 2

A 53-year-old woman $(60 \mathrm{~kg})$ with seropositive erosive rheumatoid arthritis, without systemic complications, but unresponsive to previous 'second line' therapy with sulphasalazine was admitted to the trial. Her symptoms were poorly controlled on azapropazone. At the onset of the study her ESR was $76 \mathrm{~mm} / \mathrm{h}$, CRP $51 \mathrm{mg} / \mathrm{l}$, Hb $13.3 \mathrm{~g} / \mathrm{dl}$, ferritin 117.5 $\mu \mathrm{g} / \mathrm{l}$, serum Fe $8 \cdot 1 \mu \mathrm{mol} / \mathrm{l}$, total Fe binding capacity $43.8 \mu \mathrm{mol} / 1$ (\% saturation 18.5). The patient received 14 daily intramuscular injections of $1 \mathrm{~g}$ of DFX. Electrophysiological testing during her first week of treatment showed a normal but borderline EOG result $(160 \% \mathrm{~L}, 154 \% \mathrm{R})$. At the end of the treatment period the EOG had, if anything, deteriorated slightly, (152\% L, 146\% R). Visual acuity, funduscopy, and electroretinography remained normal and unchanged throughout. Three weeks later the EOG was repeated and appeared to have improved (174\% L, 160\% R). A parallel study on five rheumatoid patients who had a similar number of EOGs carried out over a similar time period showed a maximum variation in the EOG of $16 \%$. We therefore considered that the improvement in the EOG was, at least in the left eye, significant. At the end of the study the patient felt much improved, but no clinical or laboratory index indicated reduction in disease activity. Her indices in all respects were unchanged. A bone marrow examination showed an absence of stainable iron. Follow-up over the next six months has revealed no new side effects or visual disturbance.

PATIENT 3

A 75 -year-old woman (45 kg) with seropositive 
erosive rheumatoid disease with mild Sjögren's syndrome and unresponsive to 'second line therapy' was admitted to the trial. She was taking methyldopa 250 mg per day and bendrofluazide $2.5 \mathrm{mg}$ for mild hypertension, and prednisolone EC $10 \mathrm{mg}$ and diclofenac $50 \mathrm{mg}$ three times a day for the arthritis. At the onset of the study her ESR was $80 \mathrm{~mm} / \mathrm{h}$, CRP $92 \mathrm{mg} / 1, \mathrm{Hb} 12.5 \mathrm{~g} / \mathrm{dl}$, ferritin $81 \mu \mathrm{g} / \mathrm{l}$, serum iron 5.3 $\mu \mathrm{mol} / /$, total $\mathrm{Fe}$ binding capacity $62 \mu \mathrm{mol} / /$ (\% saturation 8.5). The EOG prior to treatment with DFX was at the lower limit of our normal range $(154 \% R, 150 \% \mathrm{~L})$. Visual acuity was $6 / 6 \mathrm{R}$ and $\mathrm{L}$. She received five $1 \mathrm{~g}$ daily intramuscular injections of DFX. Twenty hours after the last injection the patient developed profound visual symptoms, with visual acuity reduced to $4 / 36 R$ and counting fingers L. Posterior pole retinal oedema and pigmentary epitheliopathy were diagnosed by fluorescein angiography. The EOG was grossly subnormal $(100 \% \mathrm{R}$, $86 \%$ L-inverted). The ERG revealed normal scotopic responses consistently of higher amplitude from the $R$ eye $(530 \mu V R, 420 \mu V$ L, normal $=>300$ $\mu V)$. The red flicker ERGs were slightly reduced in the right eye $(45 \mu \mathrm{V}$; normal $>60 \mu \mathrm{V})$ and reduced in the left eye $(30 \mu \mathrm{V})$ but with no delay. This was consistent with the fundus appearance and the grossly impaired visual acuity. The oscillatory potentials of the ERG, reflecting the integrity of the vascular supply to the retina, were normal. VERs revealed reduced amplitudes in both eyes $(3 \mu \mathrm{V} R$, $2 \mu \mathrm{VL}$, normal $>4 \mu \mathrm{V}$ ) but no evidence of delay.

All tests were repeated three weeks later. The posterior pole oedema had largely resolved, leaving pigment epithelial atrophy and mottled hyperfluorescence. Visual acuity had improved to $6 / 6 \mathrm{R}$ and 6/12 L. The EOG had improved considerably $(180 \% \mathrm{R}, 150 \% \mathrm{~L})$. The scotopic ERG had deterior-

Table 1 Desferrioxamine-induced copper removal from albumin

\begin{tabular}{llll}
\hline $\begin{array}{llll}\text { Time } \\
\text { (h) }\end{array}$ & Copper $(\mathrm{ng} / \mathrm{ml})$ & \\
\cline { 2 - 4 } & Desferrioxamine & $\begin{array}{l}\text { Desferrioxamine } \\
+ \text { methyldopa }\end{array}$ & \\
\hline $0 \cdot 5$ & $12(0 \cdot 5)$ & $19(2)$ & $\mathrm{p}<0 \cdot 02$ \\
2 & $14(1)$ & $16(2)$ & NS \\
7 & $19(1)$ & $20(4)$ & NS \\
\hline
\end{tabular}

Albumin and transferrin (plasma concentrations) were incubated in HEPES $\left(80 \mathrm{mM}, \mathrm{pH} \mathrm{7.4)}\right.$ containing $\mathrm{HCO}^{3-}(27 \mathrm{mM})$, copper $(100$ $\mathrm{ng} / \mathrm{ml})$, and iron $\left(3.3 \times 10^{-5} \mathrm{M}\right)$ for $18 \mathrm{~h}$. Desferrioxamine $\left(10^{-5} \mathrm{M}\right)$ in the presence and absence of methyldopa $\left(10^{-5} \mathrm{M}\right)$ was added, and aliquots $(2.5 \mathrm{ml})$ were removed at different times and filtered with an Amicon YM5 membrane (5000 molecular weight cut-off). The filtrate was analysed for both iron and copper $(n=4)$ by atomic absorption spectrophotometry. Results are expressed as the mean of four determinations (SEM in parentheses). ated to $320 \mu \mathrm{V} R$ and $240 \mu \mathrm{V} \mathrm{L}$, left eye responses now being abnormal. However, the flicker ERG had improved to within normal limits $(74 \mu \mathrm{V} R, 66 \mu \mathrm{V}$ L). The VER had also improved $(6 \mu V R, 5 \mu \mathrm{VL})$ to normal. A final assessment seven weeks after the visual episode revealed no change in the EOG or scotopic ERG, but the VER and flicker ERG had further improved. Visual acuity was recorded at $6 / 6 \mathrm{R}$ and 6/9 L. From our test protocol the ERG changes suggest a deterioration of rod function but an improvement in cone function. A bone marrow biopsy was performed two weeks after the DFX had been started and showed only occasional small Perlspositive iron fragments in the reticuloendothelial meshwork. At this stage her serum iron, total iron binding capacity, and ferritin were unaltered from baseline values.

\section{CSF STUDIES}

At the time our third patient developed ocular symptoms, patients 1 and 2 had received 14 intramuscular injections (the maximum to be given under the protocol). Patient 1 had suffered no side effects, but patient 2 had developed an abnormal EOG. The ocular side effects, occurring in patient 3 , were discussed with the two other patients. In view of our previous experience ${ }^{1}$ we were interested in establishing whether loosely bound, non-caeruloplasminbound copper with the capacity to induce oxidative damage (phenanthroline copper) was altered in any of these patients' CSF. CSF has many features in common with aqueous humour, and we reasoned that what happened in one fluid may also happen in the other. After discussion patients 1 and 2 agreed to a lumbar puncture examination; it was considered unreasonable to request this investigation from patient 3, as she was elderly and distressed by her visual loss. Patient 1 , without ocular problems, had a normal $\mathrm{Cu}$ concentration $(1.8 \mu \mathrm{M})($ normal $1.5(0.5)$ $\mu \mathrm{M}$ (mean, SD)). In patient 2 , with an abnormal EOG, the Cu level was considerably raised $(3.4 \mu \mathrm{m})$. No correlation has been found between CSF loosely bound copper and age or sex in any of the groups studied so far. ${ }^{\circ}$

\section{CHEMICAL CONSIDERATIONS}

Although DFX is generally considered to be a specific iron (III) chelator, it has an appreciable affinity for copper (II) (affinity constant $10^{32}$ for $\mathrm{Fe}(\mathrm{III}) ; 10^{14}$ for $\mathrm{Cu}(\mathrm{II}),{ }^{8}$ particularly under physiological conditions where a number of endogenous high affinity iron (III) binding sites will compete with DFX for the limited iron pool. In an attempt to assess the ability of DFX to scavenge copper under conditions similar to those found in human plasma DFX was incubated with a solution of albumin and trans- 
ferrin (30\% saturated with iron) at physiological concentrations. DFX mobilised a significant proportion of the added copper ( $15 \%$ after 2 hours, Table 1 ); indeed proportionally more copper than iron was chelated by DFX, under these conditions. Interestingly, the inclusion of methyldopa, which patient 3 had received during the trial, in this system increased the rate of exchange of copper between albumin and DFX (Table 1). Thus a possible cause of synergism between DFX and methyldopa is the enhanced mobilisation of plasma copper.

Methyldopa, by analogy with most substituted catechols, is capable of chelating copper (II), ${ }^{9}$ forming highly water soluble complexes which will not permeate membranes as rapidly as the copper-DFX complex. Thus under conditions of high local methyldopa concentrations DFX-induced elevated copper levels could have prolonged lifetimes. This possibility was invesigated by means of Pressman cells. We previously showed that DFX can facilitate the movement of iron across non-aqeuous phases.' In this study we show that DFX can also facilitate copper movement (Fig. 1). However, methyldopa, when present at a concentration equimolar with that of DFX, inhibits this translocation process, presumably by forming a water soluble copper complex. Thus a second interaction between DFX and methyldopa, centred on the ability of both drugs to co-ordinate copper, is also possible.

\section{Discussion}

Despite suggestions that DFX is efficacious in low dosage in patients with rheumatoid arthritis and is without 'reported' side effects, ${ }^{3}$ our results clearly indicate that even at this dose the therapeutic index is too low to justify further use in such patients. Our results also support the view that toxicity is related to the level of iron stores. ${ }^{10}$ Quite apart from considerations of age, the differences in iron stores between patients with rheumatoid arthritis and those with thalassaemia may explain the apparent higher risk of toxicity in the former group. It is of interest that in patients with $\beta$ thalassaemia who also develop neuroophthalmic symptoms despite high iron stores ${ }^{9}$ DFX increases urinary copper excretion. ${ }^{11}$ Furthermore, the results highlight the difficulty in assessing iron stores in a rheumatoid population from assessments of serum ferritin, serum iron, and iron binding capacity. We and others have suggested that a serum ferritin $>50 \mu \mathrm{g} / \mathrm{l}$ implies adequate iron stores in the presence of inflammation; ${ }^{12} 13$ this appears to be incorrect. It is clear that both of our patients who developed ocular lesions had reduced iron stores, though the one patient who did not was also probably iron depleted. Our in-vitro data (Table 1, Fig. 1)

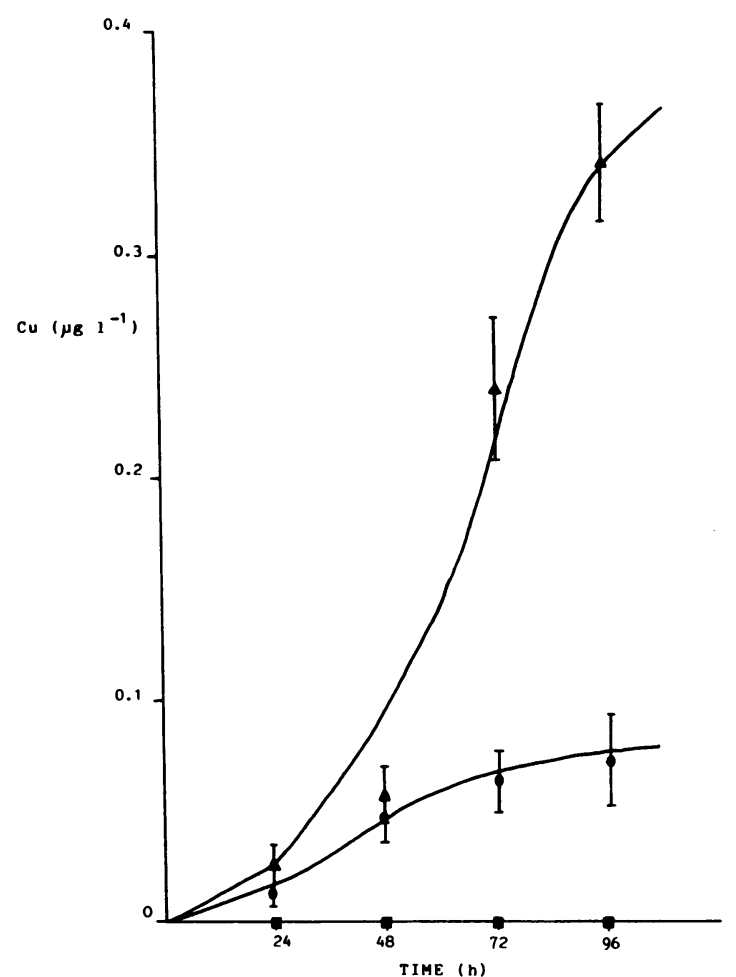

Fig. 1 The rate of copper movement through a chloroform phase as catalysed by the presence of desferrioxamine. $A$ Pressman cell was constructed such that chloroform $(6 \mathrm{ml})$ separated two aqueous compartments $A$ and $B(6 \mathrm{ml} M O P S$, $20 \mathrm{mM}, \mathrm{pH} 7 \cdot 4)$. The two aqueous solutions were continuously stirred mechanically. Copper (II) nitrilotriacetate $\left(1 \mathrm{mg} / \mathrm{l}^{-1}\right.$ copper; $\left.10^{-4} \mathrm{M} N \mathrm{NA}\right)$ was added to side $A$. Samples were taken from side $B$ every $24 \mathrm{~h}$ and analysed for copper by atomic absorption

spectrophotometry. , desferrioxamine $(1 \mathrm{mM})$ added to side $B ; \triangle$, desferrioxamine ( $1 \mathrm{mM})$ added to side $B$ and methyldopa ( $1 \mathrm{mM}$ ) added to side $A ; 0$, no addition to either side $A$ or $B$. All the results are the mean of at least three individual determinations $\pm S E M$.

suggest that in such circumstances, when transferrin is not saturated, DFX will chelate copper and has the potential of translocating this metal across membranes. The additional observation that methyldopa has the potential of interacting synergistically with DFX, both in plasma to release copper and in cells to trap copper, offers an explanation for the accelerated development of severe toxicity in patient 3 and bears analogies with the interaction of DFX with prochlorperazine that we have reported previously. ${ }^{1}$

The most significant ocular electrophysiological finding in our patients were the disturbances in the EOG. In patient 3 these rapidly became subnormal and then quickly improved. The origin of the EOG, a 
test which has been used for monitoring chloroquine toxicity among other conditions remains a debated subject. It is reported that the electro-ocular potential originates between the RPE and the external limiting membrane and is due to potassium ion fluxes across the RPE cell membranes, ${ }^{14}{ }^{15}$ the light response being due to a slow depolarisation of the basal cell membrane of the RPE. Our data, when coupled with our previous observation, strongly suggest that the copper detectable by the 'phenanthroline copper' assay, which would include desferrioxamine-bound copper, might directly or indirectly change the ionic potential across the RPE, causing a reduced electroocular potential rise during light stimulation and hence a low EOG. The retinal pigment epithelium appears to have good powers of recovery from such an insult, as no lasting changes to the EOG occurred.

In patient 3 the electroretinogram started to deteriorate to low intensity scotopic (rod) stimulation while the EOG and red flicker (cone) ERG was recovering. It remained reduced even when the EOG and flicker ERG had completely recovered. The electroretinogram assesses the functional integrity of the outer two-thirds of the retina, including rod and cone function. We presume from this observation that oxidative damage has now occurred in the rod outer segments, while the cone cells recovered in line with the resolving pigment epitheliopathy. Rapp and Williams ${ }^{16}$ and Organisciak and Noell ${ }^{17}$ have reported that light-induced oxidative damage is a function of rhodopsin content and opsin packing density in photoreceptor outer segments. In patient 3 it is possible that, despite the cones' recovering from the oxidative insult, the rod outer segments had suffered injury due to the combined effects of $\mathrm{Cu}$ and light damage. Certainly the time scale from the start of the oxidative damage of the cones to the induction of oxidative damage to the rods would correlate with the animal model findings of O'Steen and Donnelly, ${ }^{18}$ who found that the oxidative effects of light damage take several days before they are fully expressed. The current evidence suggests that the EOG should be carefully monitored during treatment with DFX.

Our data suggest that copper fluxes induced by DFX are important in mediating its ocular toxicity and that these fluxes may be exacerbated by methyldopa. Copper probably has an important role in retinal physiology, being found in high concentrations within the RPE, ${ }^{19}$ a site which is known to be affected by DFX..$^{20}$ The molecular consequences of DFX-induced copper translocation are unknown but there are numerous possibilities:

(1) Decompartmentalised copper may induce oxidative cell membrane damage via a process of lipid peroxidation which it is known to stimulate in vitro. ${ }^{21}$ Products of lipid peroxidation are known to be toxic to retinal photoreceptor cells..$^{223}$ The abundance of highly poyunsaturated fatty acids within the retina would predispose to such a process of lipid peroxidation.

(2) Movement of copper into extracellular fluids may interrupt monoaminergic neurotransmission in the retina-copper playing an important part in the synthesis of both dopamine and noradrenaline for example. The activity of the rate-limiting enzyme for dopamine biosynthesis, tyrosine hydroxylase, is reduced in states of copper deficiency, and dopamine $\beta$ hydroxylase, which converts dopamine to noradrenaline, is a copper-dependent enzyme. ${ }^{24}$

(3) Synthesis of the potential antioxidant, neuromelanin, ${ }^{25}$ may be impaired by reduction of the activity of tyrosinase, another copper-containing protein. This may also predispose the subject to increased oxidative damage.

(4) Increased concentrations of low-molecularweight/loosely bound copper ions in various subcellular locations may inhibit the activities of many molecules, including enzymes and catecholamines, possibly by promoting oxidative damage..$^{26} 27$

Although the molecular mechanism whereby DFX toxicity is mediated remains uncertain, we have presented prima facie evidence that the chelation of copper is essential to this process. It follows that the interactions between copper, iron, and DFX and other metal ligating agents such as methyldopa may, among other factors determine an individual patient's susceptibility to the ophthalmic toxicity of DFX.

We are grateful to $\mathrm{Mr}$ I Bradley for photographic assistance and to Professor P A Bacon and Dr J M C Gutteridge for their useful comments.

Financial support was received from West Midlands Regional Health Authority (UK), Ciba Geigy Pharmacueticals (Horsham UK), and Arthritis and Rheumatism Council (UK).

\section{References}

1 Blake DR, Winyard P, Lunec J, et al. Cerebral and ocular toxicity induced by desferrioxamine. $Q \mathrm{~J}$ Med $1985 ; 56: 345-55$.

2 Pall HS, Williams AC, Blake DR, Lunec J. Evidence of enhanced lipid peroxidation in the cerebrospinal fluid of patients taking phenothiazines. Lancet 1987; ii: 596-9.

3 Giordano N, Fioravanti A, Sanasciani S, Marcolongo R, Borghi C. Increased storage of iron and anaemia in rheumatoid arthritis: usefulness of desferrioxamine. Br Med J 1984; 289: 961-2.

4 Giordano N, Fioravanti A, Borghi C, Mariani AM, Sancasciani $\mathrm{S}$, Marcolongo $\mathrm{R}$. Increased iron storage and anaemia in rheumatoid arthritis: usefulness of desferrioxamine reported/ published (abstract P696); XVIth International Congress of Rheumatology (ILAR 1985), Sydney.

5 Arden GB, Barrada A, Kesley JM. New clinical test of retinal function based upon the standing potential of the eye. $\mathrm{Br} J$ Ophthalmol 1962; 46: 449-67.

6 Pall HS, Williams AC, Blake DR. et al. Raised cerebrospinal fluid copper concentration in Parkinson's disease. Lancet 1987; ii: $238-41$. 
7 Gutteridge JMC. Copper-phenanthroline induced site specific oxygen radical damage to DNA. Detection to loosely bound copper in biological fluids. Biochem $J 1984$; 218: 983-5.

8 Anderegg G, l'Eplattenier F, Schworzenbach G. Hydroxamatkomplexe III. Eisen (III) Austausch zwischer sideramines und komplexonen. Helv Chim Acta 1963; 46: 1409-22.

9 Hider RC. Siderophore mediated absorption of iron. Structure and bonding. 1984; 58: 25-87.

10 Olivieri NF, Buncic JR, Chew E, et al. Visual and auditory neurotoxicity in patients receiving subcutaneous deferoxamine infusions. N Engl J Med 1986; 314: 869-73.

11 Zaino EC. Deferoxamine and trace metal excretion in chelation therapy in chronic iron overload. In: Zaino EC, Roberts RH, eds. Chelation and chronic iron overload. New York: CIBA Medical Horizons Symposium, 1977: 95-101.

12 Blake DR, Waterworth RF, Bacon PA. Assessment of iron stores in inflammation by assay of serum ferritin concentrations. Br Med J 1981; 283: 1147-8.

13 Worwood M. Serum ferritin. In: Jacobs A, Worwood M, eds. Iron in biochemistry and medicine. London: Academic Press, 1980: 203-44.

14 Dawis SM, Niemeyer G. Theophylline abolishes the light peaks in perfused cat eyes. Invest Ophthalmol Vis Sci 1987; 28: 700-6.

15 Griff ER, Steinberg RH. Origin of the light peaks: in vitro study of Gekko gekko. J Physiol (Lond) 1982; 331: 637-44.

16 Rapp LM, Williams TB. The role of ocular pigmentation in protecting against retinal light damage. Vision Res 1980; 20: $1127-42$.

17 Organisciak DT, Noell NK. The rod outer segment phospholipid/opsin ratio of rats maintained in darkness or cyclic light. Invest Ophthalmol Vis Sci 1977; 16: 188-90.

18 O'Steen WK, Donnelly JE. Antagonistic effects of adrenalectomy and other surgical stress on light induced photoreceptor damage. Invest Ophthalmol Vis Sci 1982; 22: 1-7.
19 Bowness JM, Morton RA, Shakir MH. Distribution of copper and zinc in mammalian eyes. Occurrence of metals in melanin fractions from eye tissues. Biochem J 1952; 51: 521 .

20 Arden GB. Desferrioxamine administered intravenously by infusion causes a reduction in the ERG in rabbits anaesthetised with urethane. Hum Toxicol 1986; 5: 229.

21 Gutteridge JMC. Fluorescent products of phospholipid peroxidation: formation and inhibition in model systems. In: Armstrong D, Koppang N, Rider JA, eds. Ceroid lipofuscinosis (Batten's disease). Amsterdam: Elsevier Biomedical Press, 1982: 351-64.

22 Hiramitsu TY, Majima Y, Hasegawa Y, Hirata K. Role of lipid peroxide in the induction of retinopathy by $x$ irradiation. Nippon Ganka Gakkai Zasshi 1974; 78: 819-25.

23 Armstrong G, Hiramitsu T, Gutteridge J, Nilsson SE. Studies on experimentally induced retinal degeneration 1 . Effect of lipid peroxides on electroretinographic activity in the albino rat. Exp Eye Res 1982; 35: 157-71.

24 Hunt DM. Copper and neurological function. In: Biological roles of copper. Ciba Foundation Symposium 79. Amsterdam: Excerpta Medica, 1980: 247-66.

25 Van Woert MH, Ambani LM. Biochemistry of neuromelanin. Adv Neurol 1974; 5: 215-23.

26 Poirier J, Donaldson J, Barbeau A. The specific vulnerability of the substantia nigra to MPTP is related to the presence of transition metals. Biochem Biophys Res Commun 1985; 128: 2533.

27 Scheinberg IH, Sternlieb I. Wilson's disease. In: Smith LH Jr, ed. Major problems in internal medicine. Philadelphia: Saunders, 1984; 23: 31-4.

Accepted for publication 5 November 1987. 